Larissa Martins Araújo Santos

Reprodução do perfil de emergência em prótese sobre implante unitário, a partir de um fluxo digital: Relato de Caso

Brasília

2017 

Larissa Martins Araújo Santos

Reprodução do perfil de emergência em prótese sobre implante unitário, a partir de um fluxo digital: Relato de Caso

Trabalho de Conclusão de Curso apresentado ao Departamento de Odontologia da Faculdade de Ciências da Saúde da Universidade de Brasília, como requisito parcial para a conclusão do curso de Graduação em Odontologia.

Orientador: Profa. Dra. Cristine Miron Stefani

Co-orientador: C.D. Esp. José Lincoln Queirós Júnior

Brasília

2017 

Dedido este trabalho aos meus pais e irmãos que me apoiaram e incentivaram para que este trabalho fosse realizado.

À minha avó materna, Dona Manú (In memoriam), verdadeiramente maior exemplo de amor e coragem. 

Agradeço a Deus por ter sido meu fiel companheiro nos momentos mais difíceis da minha jornada, sustentando minhas falhas e me fortalecendo.

Aos meus pais, Joana Martins e Leonardo Araújo, que sempre apoiaram minhas escolhas e abdicaram de tempo e de muitos projetos pessoais para que eu tivesse a oportunidade de estudar e de ter uma boa formação profissional, mas também pessoal. Em especial a minha mãe, que tenho como referência e inspiração todos os dias, sempre me encorajando diante dos obstáculos.

Aos meus irmãos, Lucas Araújo e Fernanda Araújo, que admiro pela dedicação e esforço que, paralelamente a mim, buscam conquistar seus objetivos todos os dias desde que decidimos deixar o conforto do nosso lar. Sempre permaneceram ao meu lado em todos os momentos, e nunca deixaram que o desânimo, o cansaço e até mesmo a saudade submetesse. À Vitória Martins, que com muito carinho e atenção permaneceu ao lado dos meus pais enquanto não poderíamos.

Aos meus avós paternos, Paulo de Jesus e Maria Trindade, pelo exemplo de perseverança, amor e carinho dados ao longo dos anos, que fizeram com que e me tornasse um ser humano capaz de cuidar do próximo. 
À minha tia, Anizeth Martins, por ter me acolhido quando aqui cheguei, e sempre incentivou e apoiou meus estudos.

À minha madrinha, Cleusa Sousa, por ter sido presente sempre em minha vida.

Aos meus tios, Luiz Paulo, Luciano César, Laurênio Sérgio, Jucyara Araújo e Marco Antônio, por todos os conselhos e incentivo dados ao longo da minha jornada de estudos, desde o início.

Aos amigos, obtidos através da graduação, Laís Gomes, Bianca Boaventura, Victor Albuquerque, Giullia Lettieri, Luiz Machado, Ygor Almeida, Lucas Dias e Tainara Mesquita que foram fundamentais para que eu aqui chegasse. Obrigada por todo conhecimento compartilhado, queridos amigos e futuro colegas de profissão, acredito que este foi apenas o início da nossa amizade que se estende além dos limites da Universidade.

Aos amigos Bruno Carvalho e Maísa Paz, por terem sido fundamentais em meu desenvolvimento acadêmico, por todos os minutos que se proporam a me ensinar e me orientar diante dos questionamentos a cerca da profissão que compartilharemos.
Á Dandara Rodrigues, Amanda Amorim, Laura Gonçalves, Luma Gonzaga e Raissa Costa pela cumplicidade e companheirismo compartilhados dentro do Instituto Vicenta Maria, casa que nos uniu fraternalmente. 
Aos amigos do grupo Imprudentes, que estiveram presentes sempre que precisei, em especial à Marcella Araújo, Thais Alves, Amanda Villela e Lucas Marciel.

Aos professores que ao longo de todos os semestres foram capazes de transmitir conhecimento e pela paciência com que fizeram.

À Professora Dra. Cristine Miron, minha orientadora, que admiro principalmente pela forma com que lida com a profissão, pela competência com que administra a Clínica e pela capacidade de conseguir transferir, de forma clara, objetiva e com muito contentamento, o conteúdo de Periodontia. Agradeço pela oportunidade, confiança e paciência durante a realização dese trabalho.

À Professora Dra. Aline Úrsula, fundamental para a realização deste trabalho, pelo exemplo de profissional, que leva a missão da Odontologia não só em lecionar e dar suporte durante as Clínicas, mas também pelo amor e carinho com que sempre se apresenta ao lado dos alunos.

Ao Coorientador, Dr. Lincoln Queirós, pela oportunidade e confiança dada desde a participação no HD TRAINNE, até a atribuição de executar este trabalho. Por todo o conhecimento transmitido, conselhos e suporte dados durante este ano, fundamentais para o meu desenvolvimento pessoal e profissional. 
Aos técnicos e funcionários, Fred, Carlos Caetano, Janara, Beth e Carla, por toda dedicação, paciência e ensinamentos ao longo da graduação, com eles, sem dúvida, a jornada foi melhor. 
EPÍGRAFE

"Tenho em mim todos os sonhos do mundo." Fernando Pessoa 

SANTOS, Larissa Martins Araújo. Reprodução do perfil de emergência em prótese sobre implante unitário a partir de um fluxo digital: Relato de Caso. 2017. Trabalho de Conclusão de Curso (Graduação em Odontologia) - Departamento de Odontologia da Faculdade de Ciências da Saúde da Universidade de Brasília.

A inserção de ferramentas tecnológicas na prática clínica otimiza o tempo de cadeira e de planejamento, além de conferir maior previsibilidade e precisão aos procedimentos. O objetivo deste trabalho foi descrever a reprodução de um perfil de emergência protético, a partir de dente contralateral, em uma prótese supraimplantar em área estética, por meio de um fluxo digital. Foram realizadas leitura óptica do modelo de estudo e tomografia computadorizada da região do dente 12. Após as imagens tomográficas e ópticas serem manipuladas, foi gerado um arquivo para impressão do dente 22. Este foi materializado em impressora 3D e um guia cirúrgico foi prensado em acetato sobre o mesmo, para ser utilizado durante as fases de fresagem óssea e instalação do implante. Imediatamente após procedimento cirúrgico, o perfil de emergência do dente 12 foi definido pelo uso da coroa posicionada em estética imediata. Como resultados, observaramse harmonização ao sorriso e conforto à paciente. A escolha do planejamento digital aliado à execução de técnica cirúrgica guiada e fresagem do provisório, adequado para o condicionamento gengival, foi capaz de gerar o resultado planejado, conferindo ao tratamento previsibilidade e redução de intercorrências. 
SANTOS, Larissa Martins Araújo. Reproduction of the emergency profile on implant-supported single crown from a digital flow: Case Report. 2017. Undergraduate Course Final Monograph (Undergraduate Course in Dentistry) - Department of Dentistry, School of Health Sciences, University of Brasília.

The insertion of technological tools in clinical practice optimizes the time of chair and planning, besides giving greater predictability and precision to procedures. The aim of this work was to describe the reproduction of a prosthetic emergency profile, from a contralateral tooth, in an implant-supported prosthesis in aesthetic area, through a digital flow. Optical reading of the study model and computed tomography of the tooth region 12 were performed. After the tomographic and optical images were manipulated, a file was generated for the printing of the tooth 22. This was materialized in a 3D printer and a surgical guide was pressed in acetate on it, to be used during the bone milling phases and implant installation. Immediately after surgical procedure, the emergence profile of the tooth 12 was defined by the use of the crown positioned in immediate aesthetic. As results, harmonization was observed with the smile and comfort to the patient. The choice of digital planning combined with the execution of guided surgical technique and milling of the provisional, suitable for gingival conditioning, was able to generate the planned result, giving the treatment predictability and reduction of intercurrences. 

SUMÁRIO

Artigo Científico

Folha de Título

21

Resumo

23

Abstract

25

Introdução

27

Relato de caso

29

Discussão

35

Conclusão

37

Referências

38

Anexos

41

Normas da Revista

41 

ARTigo CientíFICO

Este trabalho de Conclusão de Curso é baseado no artigo científico:

SANTOS, LMA; FERNANDES, AÚR; STEFANI, CM; QUEIROS JÚNIOR, JL. Reprodução do perfil de emergência em prótese sobre implante unitário a partir de um fluxo digital: Relato de Caso. Apresentado sob as normas de publicação da Revista Implant News. 


\section{FolHA DE TÍTULO}

Reprodução do perfil de emergência em prótese sobre implante unitário a partir de um fluxo digital: Relato de Caso

Reproduction of the emergency profile on implant-supported single crown from a digital flow: Case Report

Larissa Martins Araújo Santos ${ }^{1}$

Aline Úrsula Rocha Fernandes ${ }^{2}$

Cristine Stefani Miron ${ }^{3}$

José Lincoln Queirós Júnior ${ }^{4}$

1 Aluna de Graduação em Odontologia da Universidade de Brasília.

2 Professora Adjunta de Prótese Dentária da Universidade de Brasília (UnB).

3 Professora Adjunta de Periodontia da Universidade de Brasília (UnB).

${ }^{4}$ Especialista em Dentística e Prótese Dentária, clínica particular

Correspondência: Profa. Dra. Cristine Miron Stefani

Campus Universitário Darcy Ribeiro - UnB - Faculdade de Ciências da Saúde - Departamento de Odontologia - 70910-900 Asa Norte - Brasília - DF

E-mail: cmstefani@gmail.com / Telefone: (61) 31071803 


\section{Resumo}

Reprodução do perfil de emergência em prótese sobre implante unitário a partir de um fluxo digital: Relato de Caso

Resumo

A inserção de ferramentas tecnológicas na prática clínica otimiza o tempo de cadeira e de planejamento, além de conferir maior previsibilidade e precisão aos procedimentos. O objetivo deste trabalho foi descrever a reprodução de um perfil de emergência protético, a partir de dente contralateral, em uma prótese supraimplantar em área estética, por meio de um fluxo digital. Foram realizadas leitura óptica do modelo de estudo e tomografia computadorizada da região do dente 12. Após as imagens tomográficas e ópticas serem manipuladas, foi gerado um arquivo para impressão do dente 22. Este foi materializado em impressora 3D e um guia cirúrgico foi prensado em acetato sobre o mesmo, para ser utilizado durante as fases de fresagem óssea e instalação do implante. Imediatamente após procedimento cirúrgico, o perfil de emergência do dente 12 foi definido pelo uso da coroa posicionada em estética imediata. Como resultados, observaramse harmonização ao sorriso e conforto à paciente. A escolha do planejamento digital aliado à execução de técnica cirúrgica guiada e fresagem do provisório, adequado para o condicionamento gengival, foi capaz de gerar o resultado planejado, conferindo ao tratamento previsibilidade e redução de intercorrências.

Palavras-chave: 
CAD/CAM; Tomografia computadorizada de feixe cônico (DICOM); Implantes dentários; Perfil de emergência; Fluxo digital. 


\section{ABSTRACT}

Reproduction of the emergency profile on implant-supported single crown from a digital flow: Case Report

\section{Abstract}

The insertion of technological tools in clinical practice optimizes the time of chair and planning, besides giving greater predictability and precision to procedures. The aim of this work was to describe the reproduction of a prosthetic emergency profile, from a contralateral tooth, in an implant-supported prosthesis in aesthetic area, through a digital flow. Optical reading of the study model and computed tomography of the tooth region 12 were performed. After the tomographic and optical images were manipulated, a file was generated for the printing of the tooth 22. This was materialized in a 3D printer and a surgical guide was pressed in acetate on it, to be used during the bone milling phases and implant installation. Immediately after surgical procedure, the emergence profile of the tooth 12 was defined by the use of the crown positioned in immediate aesthetic. As results, harmonization was observed with the smile and comfort to the patient. The choice of digital planning combined with the execution of guided surgical technique and milling of the provisional, suitable for gingival conditioning, was able to generate the planned result, giving the treatment predictability and reduction of intercurrences.

Keywords 
CAD/CAM; Cone beam computed tomography (DICOM); Dental implant; Emergence profile; Workflow. 


\section{INTRODUÇÃO}

A atual demanda estética dos pacientes vem exigindo, gradativamente, uma evolução das técnicas odontológicas, assim como a associação destas com o compromisso de buscar a melhor função do sistema estomatognático. A integração entre as diferentes especialidades se mostra como um dos caminhos para atingir estes objetivos. ${ }^{1}$

A escolha de um processo reabilitador para casos de agenesia com retenção do dente decíduo é pautada em diversos fatores, e estes variam desde a abordagem ao paciente até as opções de tratamento a ele oferecidas. ${ }^{2}$

A possibilidade de um tratamento conservador deve ser oferecida levando em consideração o prognóstico do paciente. O uso de resinas compostas para reanatomização de dentes é uma das propostas reabilitadoras menos invasivas, visto que não há necessidade de desgastes prévios. Por outro lado, exige manutenção regularmente, e em casos que envolvem dentes decíduos retidos, deverá ser realizado o acompanhamento clínico e radiográfico periódico. ${ }^{3}$

Outra proposta reabilitadora é o uso de próteses parciais removíveis, seguidas pelas próteses parciais fixas, ambas com limitações quanto a espaço, higienização e adaptação. Quando a área a ser reabilitada não é extensa, como no caso da agenesia, ou ausência de apenas um elemento por outro fator, a prótese parcial removível não se torna a melhor escolha de tratamento. ${ }^{4}$ Com o advento da Implantodontia, algumas dessas limitações foram eliminadas, contudo, cada uma das soluções propostas possuem suas indicações com vantagens e desvantagens, que 
deverão ser consideradas durante a elaboração do planejamento. 5

Tendo como suporte a imagenologia, a Implantodontia apresenta, como principal ferramenta de planejamento, a Tomografia Computadorizada de Feixe Cônico. Através da Tomografia, o arquivo em DICOM (Digital Imaging and Communications in Medicine) é extraído, capaz de se comunicar com outros sistemas, sendo eles semelhantes ou não, conferindo a ele a capacidade de interoperabilidade entre sistemas computacionais e equipamentos médicos. ${ }^{6,7}$

As imagens tomográficas $2 \mathrm{D}$ precisam ser reformatadas tridimensionalmente e convertidas para um formato padrão: o arquivo STL (Standard Tessellation Language). A partir dele, as imagens obtidas podem ser manipuladas e associadas a hardwares, onde é possível a confecção de protótipos, utilizados como modelos para guias cirúrgicos e de coroas e provisórios protéticos. Os guias cirúrgicos atuam controlando a angulação da perfuração óssea, sua profundidade e localização. 8,9

Softwares, como o CAD/CAM (Computer-Aided Design/ Computer Aided Manufacturing), permitem a união desses arquivos, oferecendo ao cirurgião dentista tanto a visibilidade quanto a impressão tridimensional de estruturas ósseas, da anatomia de dentes e raízes, além da arquitetura de tecidos moles, para o planejamento cirúrgico e reabilitador. ${ }^{10}$

O uso de softwares e hardwares, no planejamento e execução de tratamentos na Odontologia, denomina-se fluxo digital. A substituição dos processos convencionais de moldagem, enceramento e fundição por leitura óptica intraoral, manipulação da imagem digital e fresagem reduzem o tempo de conclusão do caso clínico. ${ }^{5}$ 
O uso da tecnologia digital é capaz de reduzir algumas etapas de produção laboratorial, que podem acarretar em erros, e reduz o tempo de transporte entre o laboratório e a clínica, além de diminuir o desconforto gerado por procedimentos de moldagem ao paciente. Estudos realizados acerca da adaptação marginal de próteses produzidas através de um fluxo digital mostraram que existe melhor adaptação destas, comparadas com as elaboradas a partir de um fluxo de trabalho convencional. ${ }^{11,12}$

Portanto, a manipulação dos tecidos moles pós-implante é feita a partir da reprodução de uma coroa provisória capaz de propor o rearranjo tridimensional de um dente natural, guiando o tecido peri-implantar. A eliminação de etapas clínicas devido à escolha de um plano de tratamento digital e a consequente redução de intervenções, tanto cirúrgicas quanto protéticas, em zona estética, torna o tratamento mais confortável, preciso e satisfatoriamente mais estético. ${ }^{13-15}$

O objetivo deste trabalho foi descrever a reprodução de um perfil de emergência protético, a partir de dente contralateral, em uma prótese supraimplantar em área estética, por meio de um fluxo digital.

\section{Relato de CAso}

Paciente do sexo feminino, 35 anos, compareceu à clínica odontológica, tendo como queixa principal o escurecimento e tamanho reduzido do dente 22, quando comparado ao contra lateral (Figura 1). Foi realizada anamnese, onde a paciente relatou não ser portadora de doença sistêmica e não ter sofrido trauma na região em questão. No exame físico extra oral, não foi verificada 
nenhuma alteração relevante, prosseguindo para o exame físico intraoral, onde notou-se que o dente, que fora relatada queixa, tratava-se de um decíduo.

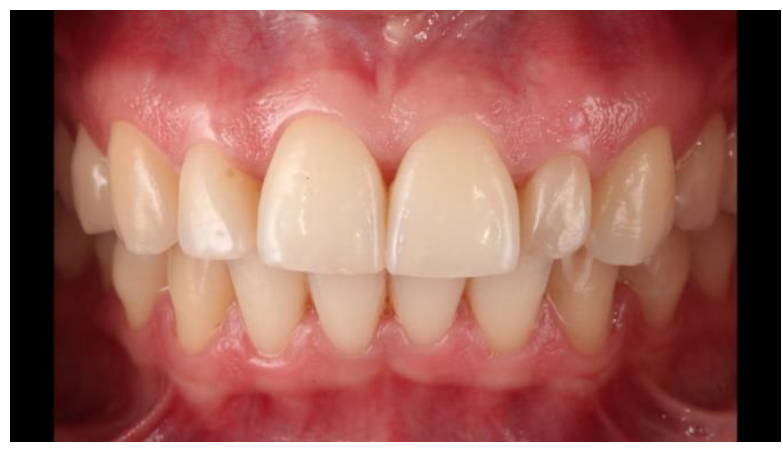

Figura 1- Fotografia Inicial

No exame radiográfico (Figura 2), foi comprovado que se tratava de um dente decíduo não esfoliado, com presença de grande reabsorção radicular interna, com separação em dois fragmentos. Dado o diagnóstico de reabsorção, optou-se pela remoção do elemento e fragmento radicular, e instalação de um implante pós extração, com provisionalização personalizada, realizada a partir de um fluxo digital. $O$ modelo digital da paciente foi obtido através do escaneamento (Trios 3, 3SHAPE, Copenhague - Dinamarca) do modelo de planejamento, realizado anteriormente a partir de molde superior de silicone de adição (Virtual Putty Regular - Ivoclar Vivadent LTDA/Barueri-SP).

Foi solicitada à paciente que realizasse tomografia computadorizada de feixe cônico do dente contra lateral e da região onde seria instalado o implante. Assim, o arquivo DICOM do exame tomográfico foi processado, permitindo a construção de protótipos de planejamento para confecção do guia cirúrgico, o 
espelhamento do dente contra lateral, e uma matriz provisória, replicando a anatomia e a forma do mesmo.

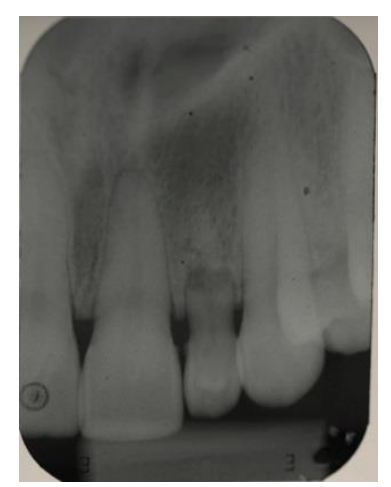

Figura 2- Imagem radiográfica de diagnóstico

Um modelo virtual foi gerado a partir da fusão dos arquivos STL original da paciente com o arquivo STL ideal do dente 22, criado a partir da tomografia (Figura 3). Este modelo serviu como simulação final do planejamento reverso.

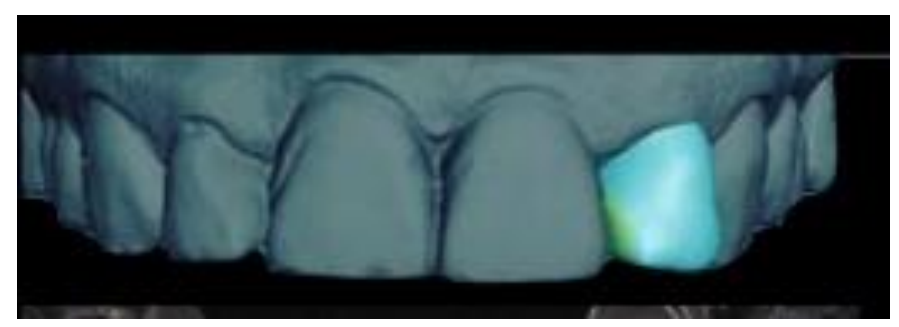

Figura 3- Planejamento a partir da fusão dos arquivos DICOM e STL, com espelhamento do dente 12 em posição 
Foi materializado o modelo do arco superior em impressora 3D (Formlabs 2 - Formlabs, EUA) (Figura 3), e um guia cirúrgico de orientação (Figura 4) foi prensado em acetato sobre o mesmo, para ser utilizado durante as fases de fresagem óssea e instalação do implante.

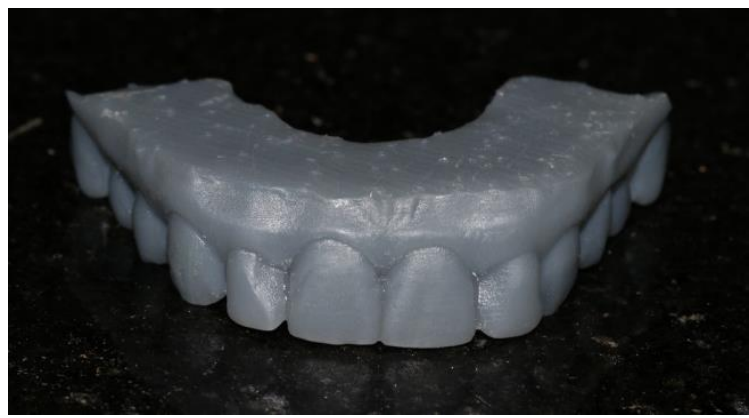

Figura 3- Modelo maxilar 3D impresso

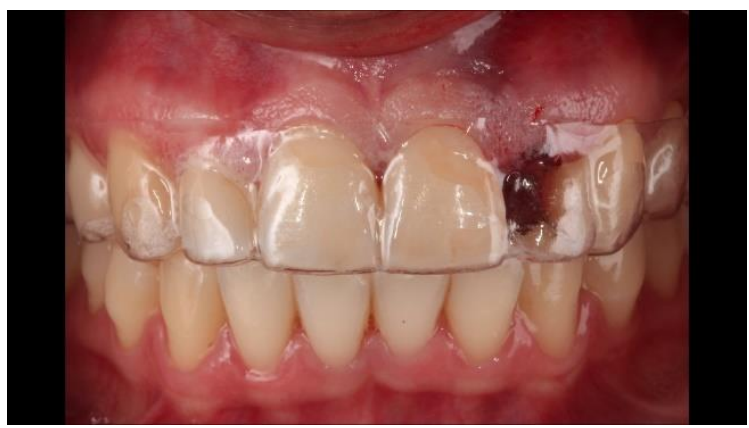

Figura 4 Guia cirúrgico em posição 
A partir da tomografia computadorizada de feixe cônico do dente contra lateral e da região onde seria instalado o implante, o dente 12 foi isolado e separado da tomografia através da diferença de densidade entre dentina/esmalte do osso alveolar e, posteriormente, convertido do formato DICOM para STL. Este foi espelhado e impresso em PMMA (Vipi Block Trilux - Vipi Produtos Odontológicos, São Paulo - Brasil), obtendo-se um provisório do dente 22, a partir das medidas do seu contra lateral.

No momento cirúrgico, o dente decíduo 62 foi extraído de forma minimamente traumática e um implante (Straumann BLT SLA Active - Villeret, Suíça) foi instalado um pilar provisório em titânio para prótese parafusada na região do dente 22 (Figura 5A), alcançando estabilidade primária em $45 \mathrm{Ncm}$. $O$ perfil de emergência da coroa foi estabelecido com a instalação da coroa sobre o implante (Figura 5B). Por meio de uma extensão do perfil crítico e subcrítico de emergência do dente previamente fresado (Ceramill motion 2, Amann Girrbach Brasil LTDA, Curitiba - PR, Brasil) em PMMA (Vipi Block Trilux - Cor A2 - Vipi Produtos Odontológicos, São Paulo - Brasil) foi posicionada a coroa em estética imediata, com ausência da incidência de forças tanto no sentido horizontal quanto vertical, conferindo, assim, a recuperação do tecido periimplantar, harmonização ao sorriso e proporcionando melhor estética gengival e conforto à paciente.

Em controle clínico e radiográfico realizado 160 dias após o procedimento cirúrgico e instalação da coroa, o provisório foi removido (Figura 5C e 5D) para avaliar a recuperação do tecido periimplantar. Este se encontrava em excelente estado biológico e estrutural, e a partir do exame radiográfico (Figura 6), o implante apresentava sinais de osseointegração, indicando a possibilidade de início do planejamento da coroa em porcelana. 


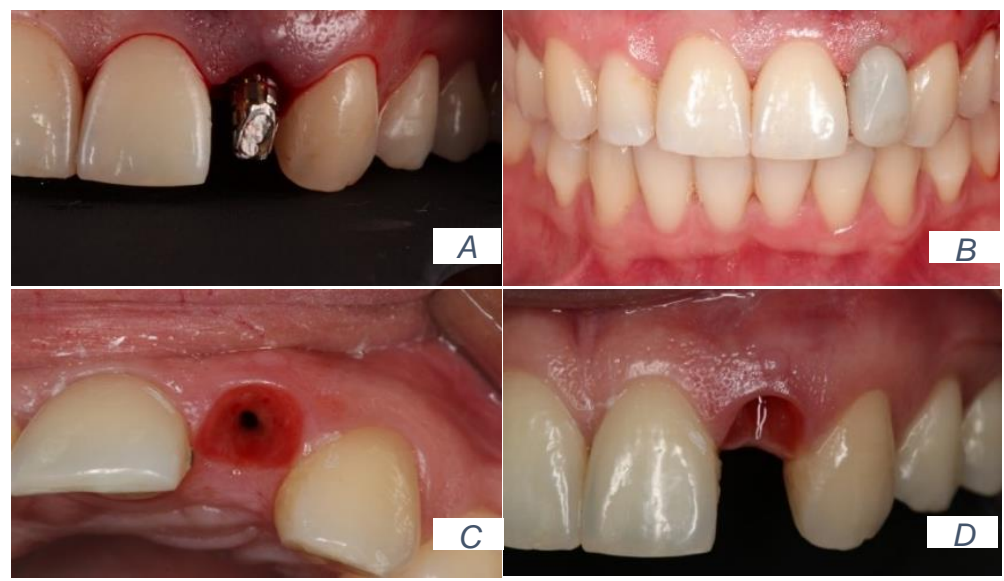

Figura 5 - Sequência clínica pós cirúrgica: A- Implante instalado com munhão de captura; B- Provisório em posição; C- Provisório removido 160 dias pós cirurgia; D- Vista frontal do provisório removido, mostrando o rearranjo tecidual definido através do design da peça protética

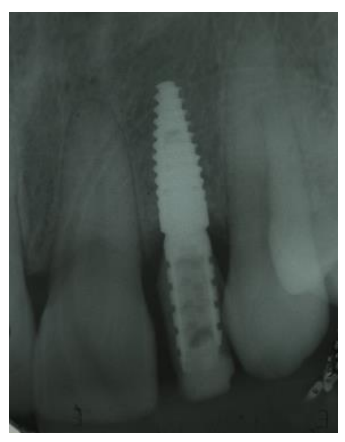

Figura 6- Imagem radiografia do implante, 160 dias após sua instalação 


\section{DIscussão}

Reabilitações em zona estética ainda têm sido um desafio para a Implantodontia, sob o ponto de vista dos fatores: técnica, tempo, conforto, resultados e custos. Em um estudo comparativo entre métodos analógicos e digitais de instalação de implantes, avaliando tempo e custo, afirmaram que a reabilitação protética pós-implante é mais eficiente através de um fluxo digital, quando comparada a métodos convencionais, reforçando a metodologia desenvolvida e apresentada no presente relato de caso. ${ }^{2,12}$ A criação de softwares a favor do planejamento vem facilitando o dia a dia clínico e reduzindo etapas de execução de tratamentos, o que confere mais conforto ao paciente e melhor aceitação aos planejamentos reabilitadores. A possibilidade de fusão de arquivos proporciona a execução de reabilitações de fluxos completamente digitais, facilitando a execução de procedimentos cirúrgicos e protéticos. ${ }^{14}$

Contudo, vale ressaltar que, não só a avaliação clínica deverá ser julgada, mas também parâmetros econômicos. A aquisição de um dispositivo de leitura óptica intraoral e de máquinas de produção, sejam estas fresadoras ou impressoras 3D, requer um investimento financeiro de alto custo, além de atualização dos softwares de design e manutenção de todo o equipamento. ${ }^{15}$

A compatibilidade de arquivos também é algo a ser considerado, levando em conta que alguns programas de execução são fechados, exigindo que o operador possua sistemas de escaneamento, manipulação de imagens e impressão que se 
comuniquem entre si. ${ }^{16} \mathrm{~A}$ digitalização, manipulação e fabricação só poderiam ocorrer em equipamentos de uma única empresa, quando se tratasse de um sistema fechado. O sistema aberto é interoperável, ou seja, é capaz de interagir com outros programas, desde que o formato do arquivo seja compatível com outras máquinas de produção, além das do próprio fabricante. Isso ocasiona maior liberdade de escolha para o operador. ${ }^{12} \mathrm{~A}$ utilização de materiais de moldagem no método convencional apresenta resultados satisfatórios quanto à precisão, contudo, deve-se obedecer alguns princípios que interferem diretamente nessa qualidade, como: variação de temperatura, tempo entre moldagem e vazamento em gesso, além de fatores que interferem na dimensão, distorcendo o material. A substituição por processos digitais reduz essas questões, mas conta com alto investimento em equipamentos. ${ }^{16}$

Mas uma avaliação de custo e eficiência para confecção de peça unitária, através de fluxo digital, mostra que, se comparada ao método convencional, obtém vantagens ${ }^{14}$, especialmente quanto à precisão conferida através de guias cirúrgicos, o que proporciona ao implantodontista maior segurança durante o procedimento. Contudo, instalação de um provisório protético indicado para o condicionamento gengival não se limita apenas à orientação da posição estrutural do implante, mas a sua qualidade e capacidade de satisfazer os requisitos básicos de manutenção dos tecidos, devendo fornecer ao paciente facilidade de higienização, formato adequado e lisura superficial. ${ }^{15,16}$

A aplicação do fluxo digital contribui para o sucesso reabilitador, na medida em que reduz ou elimina limitações que são inerentes ao trabalho manual e técnico, mas evidencia-se que não se deve substituir a necessidade de discernimento técnico do profissional 
e sua capacidade de fazer a escolha do tratamento de acordo com o desejo do paciente e as particularidades pertinentes a cada caso clínico. ${ }^{17,18}$

No presente estudo, a aplicação de um fluxo digital para reprodução do perfil de emergência, a partir de um dente contra lateral, foi capaz de promover uma reabilitação satisfatória quanto às expectativas da paciente.

\section{CONCLUSÃO}

Conclui-se que a possibilidade de execução de um plano de tratamento, a partir de um fluxo digital, é satisfatória. A sequência de etapas clínicas, com facilidade de planejamento, e a precisão proporcionada a partir da leitura óptica, prototipagem de modelos, confecção de guias cirúrgicos e reprodução de provisórios protéticos através de um dente natural espelhado resulta em um tratamento com previsibilidade de resultados. 


\section{REFERÊNCIAS}

1.Rasouli Ghahroudi AA, Homayouni A, Rokn AR, Kia $F$, Kharazifard MJ, Khorsand A. Frequency of Dental Implants Placed in the Esthetic Zone in Dental Clinic of Tehran University: A Descriptive Study. J Dent (Tehran). 2015 Dec;12(12):906-12.

2. Sailer I, Benic GI, Fehmer V, Hämmerle CHF, Mühlemann S. Randomized controlled within-subject evaluation of digital and conventional workflows for the fabrication of lithium disilicate single crowns. Part II: CAD-CAM versus conventional laboratory procedures. J Prosthet Dent. 2017 Jul;118(1):43-8.

3. Barroso IVR, Mei RMS. Reabilitação de agenesias dentárias e dente conóide - Relato de Caso. Interbio 2014; 8(2):60-7.

4. Zavanelli AC, Dekon SFC, Zavanelli RA, Mazaro JVQ, Costa, PS. Planejamento em prótese parcial fixa: Polígono de Roy. Rev Odont Unesp 2005; 26(1): 14-9.

5. Joda T, Brägger U. Digital vs. conventional implant prosthetic workflows: a cost/time analysis. Clin Oral Implants Res. 2015, 26(12):1430-5.

6. Vafiadis D, Goldstein G, Garber LA, Kowalski B. Immediate Implant Placement of a Single Central Incisor Using a 
CAD/CAM Crown-Root FormTechnique: Provisional to Final Restoration. J Esthet Restor Dent. 2017, 29(1):13-21.

7. DICOM Standards Committee. DICOM Home Page. [Acessado em: 04/07/2017]. Disponível em:http://medical.nema.org

8. Meurer MA, Meurer E, Silva JVL, Bárbara AS, Nobre LF, Oliveira $M G$, Silva DN. Aquisição e manipulação de imagens por tomografia computadorizada da região maxilofacialvisando à obtenção de protótipos biomédicos. Radiol Bras 2008;41(1):49-54.

9. Whitley D, Eidson RS, Rudek I, Bencharit S. In-office fabrication of dental implant surgical guides using desktop stereolithographic printing and implant treatment planning software: A clinical report. J Prosthet Dent. 2017 Sep; 118(3): 256-63.

10. Beuer F, Schweiger J, Edelhoff D. Digital dentistry: an overview of recent developments for CAD/CAM generated restorations. Br Dent J. 2008 May 10; 204(9):505-11.

11. Chochlidakis KM, Papaspyridakos P, Geminiani A, Feng IJ, Ercoli C. Digital versus conventional impressions for fixed prosthodontics: A systematic review and meta-analysis. J Prosthet Dent 2016; 116(2): 184-90.

12. Rayyan MM, Abousheilib M, Sayed NM, Ibrahim A, Jimbo R. Comparison of interim restourations fabricated by CAD/CAM with those fabricated manually. J Prosthet Dent. 2015 Sep; 114(3):414-9. 
13. Joda T, Brägger Urs. Digital vs. conventional implant prosthetic workflows: a cost/time analysis. Clin Oral Implants Res 2015; 26(12): 1430-5.

14. Monaco C, Evangelisti E, Scotti R, Mignani G, Zucchelli G. A fully digital approach to replicate peri-implant soft tissue contours and emergence profile in the esthetic zone. Clin Oral Implants Res. 2016, 27(12):1511-4.

15. Liu X, Liu J, Mao H, Tan J. A digital technique for replicating peri-implant soft tissue contours and the emergence profile. J Prosthet Dent. 2017 Sep; 118(3): 264-7.

16. Priest, G. Developing optimal tissue profiles implant-level provisional restorations. Dent Today 2005; 24(11): 96, 98, 100.

17. SteinmassI PA, Klaunzer F, Steinmassl O, Dumfahrt $H$, Grunert I. Evaluation of Currently Available CAD/CAM Denture Systems. J Prosthodont. 2017, 30(2):116-22.

18. Joda T, Ferrari M, Braegger U. A digital approach for one-step formation of the supra-implant emergence profile with an individualized CAD/CAM healing abutment. J Prosthodont Res. 2016, 60(3):220-3. 
ANEXos

\section{NORMAS DA REVISTA}

Relato de caso(s) clínico(s)

Deverão conter: título em português, nome(s) do(s) autor(es), titulação do(s) autor(es), resumo, unitermos, introdução e/ou proposição, relato do(s) caso(s) clínico(s), discussão, conclusão, nota de esclarecimento, título em inglês, resumo em inglês (abstract), unitermos em inglês (keywords) e referências bibliográficas.

Limites: texto com, no máximo, 18.000 caracteres (com espaços), 2 tabelas ou quadros, 2 gráficos e 32 figuras.

- Formatação de página:

- Margens superior e inferior: $2,5 \mathrm{~cm}$

- Margens esquerda e direita: $3 \mathrm{~cm}$

- Tamanho do papel: carta

- Alinhamento do texto: justificado

- Recuo especial da primeira linha dos parágrafos: $1,25 \mathrm{~cm}$

- Espaçamento entre linhas: 1,5 linhas

- Controle de linhas órfãs/viúvas: desabilitado

- As páginas devem ser numeradas

- Formatação de texto:

- Tipo de fonte: times new roman 
- Tamanho da fonte: 12

- Título em português: máximo de 90 caracteres

- Titulação do (s) autor (es): citar até 2 títulos principais

- Resumos em português e inglês: máximo de 250 palavras cada

- Unitermos e keywords: máximo de cinco. Consultar Descritores em Ciências da Saúde - Bireme (www.bireme.br/decs/)

- Citações de referências bibliográficas

- No texto, seguir o Sistema Numérico de Citação no qual somente os números índices das referências, na forma sobrescrita, são indicados no texto.

- Números sequenciais devem ser separados por hífen (ex.: 4-5); números aleatórios devem ser separados por vírgula (ex.: 7, 12, 21).

- Não citar os nomes dos autores e o ano de publicação Exemplos: Errado: "Bergstrom J, Preber H 2 (1994)". Correto: "Vários autores 1,5,8 avaliaram que a saúde geral e local do paciente é necessária para o sucesso do tratamento"; "Outros autores 1-3 concordam..."

\section{- REFERÊNCIAS BIBLIOGRÁFICAS}

- Quantidade máxima de 30 referências bibliográficas por trabalho.

- A exatidão das referências bibliográficas é de responsabilidade única e exclusiva dos autores.

- A apresentação das referências bibliográficas deve seguir a normatização do estilo Vancouver, conforme orientações fornecidas pelo International 
Committee of Medical Journal Editors (www.icmje.org) no "Uniform Requirements for Manuscripts Submitted to Biomedical Journals".

- Os títulos de periódicos devem ser abreviados de acordo com o "List of Journals Indexed in Index Medicus" (www.nlm.nih.gov/tsd/serials/ji.html) e impressos sem negrito, itálico ou grifo/sublinhado.

- As referências devem ser numeradas em ordem de entrada no texto pelos sobrenomes dos autores, que devem ser seguidos pelos seus prenomes abreviados, sem ponto ou vírgula. A vírgula só deve ser usada entre os nomes dos diferentes autores. Incluir ano, volume, número (fascículo) e páginas do artigo logo após o título do periódico. Exemplo: "1. Lorato DC. Infl uence of a composite resin restoration on the gengival. Prosthet Dent 1992;28:402-4. 2. Bergstrom J, Preber H. Tobaco use as a risk factor. J Periodontal 1994;65:545-50. 3. Meyer DH, Fives-Taylor PM. Oral pathogens: from dental plaque to cardiace disease. Cure opin microbial; 1998:88-95."

- Nas publicações com até seis autores, citam-se todos.

- Nas publicações com sete ou mais autores, citamse os seis primeiros e, em seguida, a expressão latina et al.

- Deve-se evitar a citação de comunicações pessoais, trabalhos em andamento e os não publicados; caso seja estritamente necessária sua 
citação, as informações não devem ser incluídas na lista de referências, mas citadas em notas de rodapé.

- Exemplos

- Livro: Brånemark P-I, Hansson BO, Adell R, Breine $\mathrm{U}$, Lindstrom J, Hallen $\mathrm{O}$, et al. Osseointegrated implants in the treatment of the edentulous jaw. Experience form a 10-year period. Scan J Plastic Rec Surg 1977;16:1-13.

- Capítulo de livro: Baron, R. Mechanics and regulation on ostoclastic boné resorption. In: Norton, LA, Burstone CJ. The biology of tooth movement. Florida: CRC, 1989. p. 269-73.

- Editor(es) ou compilador(es) como autor(es): Brånemark P-I, Oliveira MF, editors. Craniofacial prostheses: anaplastology and osseointegration. Illinois: Quintessence;1997.

- Organização ou sociedade como autor: Clinical Research Associates. Glass ionomer-resin: state of art. Clin Res Assoc Newsletter 1993;17:1-2.

- Artigo de periódico: Diacov NL, Sá JR. Absenteísmo odontológico. Rev Odont Unesp 1988;17(1/2):183-9.

- Artigo sem indicação de autor: Fracture strenght of human teeth with cavity preparations. J Prosth Dent 1980;43(4):419-22.

- Resumo: Steet TC. Marginal adaptation of composite restoration with and without $\mathrm{fl}$ owable liner [resumo]. J Dent Res 2000;79:1002. 
- Artigo citado por outros autores apud: Sognnaes RF. A behavioral courses in dental school. J Dent Educ 1977;41:735-37 apud Dent Abstr 1978;23(8):408-9.

- Dissertação e tese: Molina SMG. Avaliação do desenvolvimento físico de pré-escolares de Piracicaba, SP [tese]. Campinas: Universidade Estadual de Campinas;1997.

- Trabalho apresentado em evento: Buser D. Estética em implantes de um ponto de vista cirúrgico. In: $3^{\text {o }}$ Congresso Internacional de Osseointegração: 2002; APCD - São Paulo. Anais. São Paulo: EVM; 2002. p. 18.

- Artigo em periódico on-line/internet: Tanriverdi et al. $\mathrm{Na}$ in vitro test model for investigation of desinfection of dentinal tubules infected whith enterococcus faecalis. Braz Dent J 1997,8(2):6772. [Online] Available from Internet <http://www.forp.usp.br/bdj/t0182.html>. [cited 30-6-1998]. ISSN 0103-6440.

\section{- TABELAS OU QUADROS}

- Devem constar sob as denominações "Tabela" ou "Quadro" no arquivo eletrônico e ser numerados em algarismos arábicos.

- A legenda deve acompanhar a tabela ou o quadro e ser posicionada abaixo destes ou indicada de forma clara e objetiva no texto ou em documento anexo. 
- Devem ser autoexplicativos e, obrigatoriamente, citados no corpo do texto na ordem de sua numeração.

- Sinais ou siglas apresentadas devem estar traduzidos em nota colocada abaixo do corpo da tabela/quadro ou em sua legenda.

\section{- FIGURAS/IMAGENS}

- Devem constar sob a denominação "Figura" e ser numeradas com algarismos arábicos.

- A (s) legenda(s) deve(m) ser fornecida(s) em arquivo ou folha impressa à parte.

- Devem, obrigatoriamente, ser citadas no corpo do texto na ordem de sua numeração.

- Sinais ou siglas devem estar traduzidos em sua legenda.

- Na apresentação de imagens e texto, deve-se evitar o uso de iniciais, nome e número de registro de pacientes. O paciente não poderá ser identificado ou estar reconhecível em fotografias, a menos que expresse por escrito o seu consentimento, o qual deve acompanhar 0 trabalho enviado.

- Devem possuir boa qualidade técnica e artística, utilizando o recurso de resolução máxima do equipamento/câmera fotográfica.

- Devem ser enviadas gravadas em CD, com resolução mínima de 300dpi, nos formatos TIF ou JPG e largura mínima de $10 \mathrm{~cm}$.

- Não devem, em hipótese alguma, ser enviadas incorporadas a arquivos de programas de 
apresentação (PowerPoint), editores de texto (Word for Windows) ou planilhas eletrônicas (Excel).

- GRÁFICOS

- Devem constar sob a denominação "Gráfico", numerados com algarismos arábicos e fornecidos, preferencialmente, em arquivo à parte, com largura mínima de $10 \mathrm{~cm}$.

- A legenda deve acompanhar o gráfico e ser posicionada abaixo deste.

- Devem ser, obrigatoriamente, citados no corpo do texto, na ordem de sua numeração.

- Sinais ou siglas apresentadas devem estar traduzidos em sua legenda.

- As grandezas demonstradas na forma de barra, setor, curva ou outra forma gráfica devem vir acompanhadas dos respectivos valores numéricos para permitir sua reprodução com precisão. 